\title{
Assessing Higher Education: Relevance of Vision and Mission Statements: A Case Study of USIU
}

\author{
Elsie Opiyo-Newa
}

\begin{abstract}
United States International University (USIU) has recently been going through workshops and training about the education effectiveness and learning outcomes of its programs. The article examines whether the learning outcomes of USIU are being instilled in the student's academic and personal lives. Learning outcomes of USIU are very important throughout a student's academic life however, there are no set mechanisms of finding out if the stated learning outcomes are being achieved.

The main objective of this study is to find out the level of awareness of the USIU vision and mission outcomes among the university students. It also aims at providing ideas on how best the vision and mission outcomes can be communicated effectively to the university community.

This preliminary study is an important step in higher education assessment where visions and missions are stated boldly without due attention to the learning processes among students. For instance, when we talk of higher order thinking, is the student able to collect, analyze and demonstrate data or information to formulate conclusions with a critically and creatively holistic manner? How do we evaluate the assimilation of the mission and vision statements?
\end{abstract}

\subsection{Introduction}

United States International University is the oldest private secular university in Eastern Africa. It is one of the key players in the region in terms of its diverse curricula and faculty. The philosophy of USIU is to promote global understanding and cooperation through education. The USIU experience expands minds, modifies beliefs and values, and motivates students for life-long learning. Indeed, students are encouraged to develop their intellectual potential and character by actively participating in their own education.

The Vision of USIU is: 'to be a premier institution of academic excellence with a global perspective in East Africa.' (USIU Catalogue 2008) This is important because it provides guidelines on where we want to be as an institution more so to the students who graduate from the university upholding its vision.

Mission and vision statements are of fundamental importance for every organization. It is said that without a vision people perish. A mission statement summarizes the basic definition and direction of an organization. By giving a mission statement the university is giving a promise to the students and society in general that if they join the institution such as USIU, they will be able to come out with the given outcomes. 
USIU is currently involved in assessing its education effectiveness and learning outcomes. According to the Centre of Learning and Teaching (CELT), Learning outcomes are very important throughout a student's academic life in the university because the student is able to know what is expected of them at the end of their course or program. There are no ambiguous expectations hence students are able to study more effectively when they know what they are working towards.(Leskes,A 2005)

Currently at USIU there are no set mechanisms of finding out if the USIU mission outcomes are being achieved.

This article examines whether the students are able to understand, explain and recognize the USIU vision and mission outcomes. It will further examine to what extent the students have internalized the mission outcomes of the institution. By this USIU will be able to know whether they have met their promise of preparing the students through selected high quality undergraduate and graduate academic programs.

\subsection{Problem statement}

From the pilot study it became apparent that majority of USIU students and faculty could not state the vision and mission outcomes of the institution. The level of awareness varied amongst students and faculty in the following manner:
a. 90 percent of students are aware it exists but can recall at least one.
b. Others recall at least two mission outcomes
c. Others recall at least two or more mission outcomes,
d. Only a few are aware of all of them and what is expected from each.

As a result of this, It is apparent that the university vision and mission may not be attained and her vision may be thwarted and thus the need to accurately investigate the level of awareness and make recommendations.

\subsection{Rationale}

USIU utilizes the orientation programs, and general education courses such as the Freshmans experience, community service, Internship and senior experience courses to pass down the mission and Vision of the Institution. It is expected that by the time students complete their General Education courses, they are aware of the Vision and Mission of the institution and the mission outcomes and that they understand the importance of the mission vision so as to realize the outcomes It has been observed by the academic administrators while registering students and by some faculty teaching courses like Freshmans experience that some students feel that General Education courses are useless and a waste of money and time. They simply wait to work hard when they begin to specialize in their 
majors. The student's attitude towards General Education courses could be a hindrance in creating of awareness of the vision and mission of USIU and it could also affect the students learning since the mission outcomes are achieved through a majority of courses offered in the university. This disconnect could be a source of miscommunication between the promise of the university to society (Students).

Findings from Benefits of learning outcomes UCE Birmingham guide to Learning Outcomes and what graduates possess, (www.calstate.edu) illustrates that it is important for students to recognize that a competent graduate of an institution of higher learning must be all rounded with vast views not necessarily in their own fields of study.

This research aims at examining and contributing to the student's deeper understanding of the importance of the vision and mission statements of USIU and the mission outcomes therein. The findings of the research may also be used to determine the extent to which the senior students have integrated the mission outcomes. It will also give us direction as to how the university can increase this awareness.

From this the researcher will be able to answer the following questions.

1. What is the level of awareness of the learning outcomes?

2. Is USIU effectively communicating its mission and learning outcomes?

3. How is USIU communicating its mission outcomes to the students and faculty?

\subsection{Objectives}

This study aims at finding out the level of awareness of the vision and mission outcomes of USIU among the university students.

It also aims at providing ideas on how best the vision and mission outcomes can be communicated to the students and the university community.

\subsection{Literature Review}

The Vision for USIU is 'that United States International University will be the premier institution of academic excellence with a global perspective in East Africa'(USIU Catalogue 2008).

According to Creighton University, 'a mission statement is important because it addresses the basic need for definition and direction. It defines the purpose of an organization and the values and ethical principles by which the members aspire to live. 
It has numerous benefits in the sense that it makes it easier to define the actions and goals that will help you achieve your vision, acts as a yardstick against which you can measure current reality and progress and also helps you evaluate your values.' (http: www 2.// Creighton .eduP.1)

USIU-Nairobi was established in 1969. It is the oldest and the largest private, secular university in East Africa. The population of USIU has grown progressively over the years from a handful of 300 students in the last sixteen years to over 4,200 students currently based in over 100 acre plot in Kasarani. There are over 45 nationalities represented in the USIU student community. USIU prepares students to live and work in a multicultural, multi-national environment. The International curriculum takes the best from the diverse learning cultures. The mission of USIU Nairobi has developed from the old mission statement of the original USIU San Diego, 'The university's mission is too promote the discovery and application of knowledge, the acquisition of skills, and the development of intellect, and character in a manner which prepares students to contribute effectively and ethically as citizens of a changing and increasingly technological world.' (USIU Catalogue 1999) there was no vision. The current mission of USIU is "to promote the discovery and the application of knowledge, acquisition of skills and the development of intellect and character in a manner that prepares students to contribute effectively and ethically as citizens of a changing and increasingly technological world".

(USIU Catalogue 2008).USIU(Nairobi) initially part of the USIU Sandiego has since been independent and is accredited by both the CHE Commission for higher education Kenyan government and the WASK Western association of schools and colleges in the United states of America.

According to the USIU catalogue 2008, This mission is achieved through selected high quality undergraduate and graduate academic programs which result in the following outcomes: Higher order thinking, Literacy, Global understanding and multicultural perspective, Preparedness for career and community service. The USIU philosophy is based on the concept global understanding and cooperation through education.

The University community has put up the vision and mission outcomes in the yearly catalogues. All new students are given catalogues during orientation and the vision and mission stated to them. The university has also communicated the vision and mission outcomes through courses like freshman's experience and senior experience. Students also experience the vision during internships and community service programs. This is also emphasized during faculty workshops and meetings.

It is our hope that when the USIU graduates understand the USIU Vision and Mission then they would be able to graduate and demonstrate our Mission outcomes. Hence the concern here is how the Mission statements and the outcomes have been communicated over the years to both the faculty and the students. This would determine the level of awareness. 
Effective program mission statements should be consistent with the campus mission statement and should be written in a language that can be understood by potential students and their families. The mission statement might provide a brief history of the program and might describe the philosophy of the program, the types of students it serves, the type of professional training it provides, the relative emphasis on teaching, scholarship and service, and important characteristics of program graduates,(Allen,2004)

Research found in http://web.cba.neu.edu on the importance of effective communication shows that people in organizations typically spend $75 \%$ of their time in an interpersonal situation; thus it is no surprise to find that at the root of a large number of organizational problems is poor communication. Effective communication is an essential component of organizational success whether it is at the interpersonal, intergroup, intragroup, organizational, or external levels. The process of transmitting information from an individual or group to another is a very complex process with many sources of potential error.

\subsection{Methodology}

This is an exploratory study that seeks to establish the levels of awareness of the USIU vision and mission statements. It uses USIU as a case study.

A pilot study was done as a pre test on the freshmen and post test on the senior students about the vision and mission of USIU and how it applies to their academic lives.

The other method utilized in this paper was a review of the channels of communicating the learning outcomes at USIU in the past which have been the university catalogues, the orientation programs, FYE and SENEX courses and the USIU library. Then an exploratory study was conducted to establish the level of awareness of the USIU Vision and mission and the realization of the learning outcomes by the USIU faculty. The target population was USIU and the primary data was through interviews from both students and faculty. Other sources of data were personal observations during class sessions and during faculty meetings and informal meetings. A sample of 30 faculty, 30 freshmen, and 30 seniors were interviewed on their observations and their level of understanding of the Vision, Mission and the learning outcomes. Faculties were met at informal settings.

\subsection{Results}

Observation among faculty showed that $90 \%$ of faculty members obviously know that USIU has a vision and mission statement which can be stated vaguely. The level of awareness is different from one faculty to another. However, a very interesting observation was that $20 \%$ of faculty who are involved in administrative matters and education effectiveness like the Deans and CELT, have the Vision and mission outcomes at their finger tips and completely comprehend what they mean unlike the $80 \%$. 
On the other hand after the pre post test, $80 \%$ of students were aware that the vision and mission outcomes existed. $80 \%$ of the fresh men could not paraphrase the mission outcomes even after being taught in the first few weeks of the semester. $20 \%$ could state two or more of learning outcomes. On the other hand $90 \%$ of the senior students were aware that the mission statements existed and $80 \%$ could paraphrase them in a clear manner. The $20 \%$ that did manage to paraphrase could explain what is expected in each outcome unlike the fresh men who could not see the relevance of the outcome and how it affected their learning and personal achievement. The SENEX students could relate their experiences in the last four years and how each outcome has influenced their reasoning, analytical skills and academic growth at USIU.

Most fresh men hoped that as they continued with their academic programs they would be able to state and explain the expectation of each outcome. Some students said that the mission outcomes would only be relevant to them if they had completed their General Education courses or if they neared graduation and had completed the entire course work. Others said it had more meaning to seniors than freshmen

\subsection{Discussion and Conclusion}

The guiding purpose of this study was to find out the level of awareness and understanding of the vision and mission statement and the mission outcomes of USIU among the students and faculty members.

Based on the findings, the senior students seemed to be more aware of the mission outcomes, they knew at least three and above and were able to explain what is expected in each outcome. Majority of faculty also had an average awareness of the existence of learning outcomes but could not explain what is expected in all the five learning outcomes. This shows that the more the student moves closer to graduation or the more senior they become, the deeper they understood the vision and mission outcomes of USIU.

USIU is not effectively communicating its vision and mission outcomes to the university community. Some students do not attend orientation programs. They do not take it seriously hence miss out on the USIU expectations. The university has not been able to do much in this regard.

Students do not read their catalogues carefully to find out details of all the requirements. It is mainly used for checking courses during registration .Majority of the USIU staff do not own a catalogue. Catalogues are used for references when one is in doubt of a requirement.This hinders effective communication to all members of the university community. 
Drawing inferences from the facts, observations and questionnaire responses I draw up the conclusion that the vision and mission of the institution are very key to the students learning, Faculty and the entire USIU community. Majority of students and faculty are definitely aware of the vision and mission but not all the learning outcomes. However, a reasonable percentage of the students do not know what is expected of each learning outcome. The vision, mission and learning outcomes of USIU have not been aggressively emphasized through the appropriate channels. Be it during orientation, or during class sessions.

When all students, staff, and faculty of USIU begin to know and understand what the mission and learning outcomes are, then that would be a beginning of successful achievement of the five learning outcomes and thus a beginning of assessment criteria of each outcome. May be we need to use more effective means for advertisement as the radio, emails, during freshmen's orientation, USIU publications, through club activities, course outlines and so on to drive the point home.

The university should probably think of including the vision mission and learning outcomes in all course outlines in the institution.

\subsection{Recommendations}

An aggressive way of communicating the mission outcomes of USIU to the university community will be important in helping the university community appreciate the vision and mission outcomes of the institution.

In the case of USIU as a university, this study will stimulate ideas that will help generate new strategies for effective communication and how to incorporate the vision, mission statement and mission outcomes in all course outlines.

The university might also suggest ways on how this can be tested to activate remembrance among the students in most of the GE courses. It will be more beneficial if it began with freshmen and tested consistently until students graduate.

Faculty should assess the impact of learning on students through behavior change, knowledge, skills and character and also assess if they have successfully achieved the five learning outcomes throughout their teaching.

As a whole, the educational experience should encourage, support, and reward students for mastering program mission outcomes. In that case USIU should reciprocate and reward its students who have mastered the USIU vision and mission statement and the Learning outcomes. USIU should develop and offer cohesive curricula that are systematically aligned with program objectives. The learning 
objectives should be used to plan course activities and grading schemes as they guide curriculum planning and are the criteria for program success.

\section{References}

Allen, J.M(2004)Assessing Academic Programs in Higher Education, Anker Publishing company, Bolton, Massachusetts.

Leskes A. and Wright D. (2005) The Art and Science of Assessing General Education Outcomes. A practical Guide. A Greater Expectations publication.

Driscoll A. and Wood S. (2007) (Developing outcomes based assessment for learnercentered education. A Faculty Introduction.

Huba M. and Freed E.(2000) Learner -Centered Assessment on College Campuses. Shifting the focus from teaching to learning.

Journal of Special Education, University of Oregon.(2007) Vol.40

http://web cba.neu.edu

USIU Catalogue 1998-99 P.1

USIU Catalogue 1992-93 p1.

USIU Catalogue 2008-2009 P.3 